\title{
PRODUÇÃO E QUALIDADE DE FRUTOS DE MARACUJÁ-AMARELO EM FUNÇÃO DA TENSÃO DE ÁGUA NO SOLO
}

Jacinto de Assunção Carvalhoํㅜ, André Luiz Dias Caldas², Fátima Conceição Rezende³ , Marcus Vinícius Nakazone, Lucas do Amaral Faria ${ }^{5}$

\section{RESUMO}

O experimento foi realizado na Universidade Federal de Lavras, Brasil, entre agosto de 2007 a fevereiro de 2008, com o objetivo de avaliar os efeitos da tensão de água no solo sobre a produção e qualidade dos frutos de maracujáamarelo. O delineamento estatístico foi em blocos casualizados com quatro repetições e quatro tensões de água no solo, correspondente a $15,30,45$ e $60 \mathrm{kPa}$. A cultura foi irrigada por gotejamento quando a tensão, à $0,20 \mathrm{~m}$ de profundidade, foi equivalente ao definido para cada tratamento. Não houve efeito significativo dos tratamentos adotados, portanto a cultura pode ser irrigada quando a tensão de água no solo atinge $60 \mathrm{kPa}$, sem afetar a produção e a qualidade dos frutos.

Palavras-chave: Disponibilidade de água no solo, Classificação de Frutos, Peso de Frutos

\section{ABSTRACT \\ PRODUCTION AND QUALITY OF YELLOW PASSION FRUITS AS A FUNCTION OF SOIL-WATER SUCTION}

The experiment was carried out at the Federal University of Lavras, Brazil, from August 2007 to February 2008 in order to evaluate the effects of soil-water suction on the production and quality of yellow passion fruit. The statistical design consisted of randomized blocks with four replications and four soil-water suctions corresponding to $15,30,45$ and $60 \mathrm{kPa}$. The crops were drip irrigated when suction at the depth of $0.20 \mathrm{~m}$ was equivalent to that defined for each treatment. There was no significant effect of the adopted treatments, therefore the crop could be irrigated when the soil-water suction reached $60 \mathrm{kPa}$ without affecting production and quality of the fruits.

Keywords: Availability of soil water, Fruit Classification, Fruit Weigh

\section{Recebido para publicação em 11/03/2014. Aprovado em 09/06/2014.}

1 - Eng. Agrícola, Prof. Depto. de Engenharia, Campus da UFLA, Cep. 3037, Lavras, MG, e-mail: jacintoc@deg.ufla.br

2 - Eng. Agrícola, Mestrando em Rec. Hídricos em Sistemas Agrícolas, DEG/UFLA, e-mail: caldasagri@yahoo.com.br

3 - Eng. Agrícola, Depto. de Engenharia/UFLA, Campus Universitário, Lavras/MG, e-mail:frezende@deg.ufla.br

4 - Eng. Agrícola, DEG/UFLA, Campus da UFLA, Cx. P. 3037,

5 - Eng. Agrícola, Doutorando em Irrigação e Drenagem, ESALq, Piracicaba/SP, e-mail:lucasfr@usp.br 


\section{INTRODUÇÃO}

O maracujá é originário de regiões tropicais e encontrou no Brasil condições excelentes para o seu cultivo. Muitas substâncias presentes nos frutos, principalmente na polpa e casca, podem contribuir para efeitos benéficos tais como: atividade antioxidante, anti-hipertensão, redução da taxa de glicose e colesterol do sangue (ZERAIK et al., 2010). Ainda, de acordo com os autores, as variedades comerciais de maracujá também são ricas em alcaloides, flavanoides, carotenoides, minerais e vitaminas A e C, substâncias responsáveis pelo efeito funcional em outros alimentos.

O Brasil é considerado o principal produtor mundial de maracujá apresentando, em 2011, uma área plantada de aproximadamente 61.842 hectares com rendimento médio de $149.767 \mathrm{~kg} \mathrm{ha}^{-1} \mathrm{e}$, Minas Gerais contribuiu com 2.537 ha de área plantada com uma produção média de 38.518 toneladas (IBGE, 2013). Souza et al. (2003), trabalhando com maracujazeiro, obtiveram produtividades variando de 30 a $40 \mathrm{t} \mathrm{ha}^{-1}$.

O maracujazeiro é uma planta que floresce e frutifica em vários meses do ano e é influenciado pelo fotoperíodo, temperatura e disponibilidade hídrica. A ocorrência de déficit hídrico pode comprometer o desenvolvimento da planta $\mathrm{e}$ induzir a queda de botões florais e de frutos e reduzir o florescimento. O sistema radicular do maracujazeiro é do tipo pivotante, pouco profundo e concentrado próximo ao caule. Souza et al. (2002) verificaram que o comprimento das raízes e a área radicular reduziram-se com a profundidade do perfil e os maiores valores se concentraram na camada de 0,00-40 m.

De acordo com Souza et al. (2005), o fornecimento frequente de água permite a floração e frutificação do maracujazeiro continuamente, no entanto, para a obtenção de boas produtividades com qualidade de frutos, a água deve ser aplicada em quantidade adequada. Em trabalho realizado por Carvalho et al. (2000), utilizando seis tratamentos de irrigação $(0,25,50,75,100$ e $125 \%$ de ET $)$ verificaram que a produtividade máxima dos frutos $\left(41,3 \mathrm{t} \mathrm{ha}^{-1}\right)$ foi obtida quando se aplicou $290 \mathrm{~g}$ planta $^{-1} \mathrm{ano}^{-1}$ de $\mathrm{N}$ e lâmina de irrigação equivalente a $75 \%$ de $\mathrm{ET}_{0}$, o que corresponde a uma lâmina total (precipitação + irrigação) de $1293 \mathrm{~mm}$. Souza et al. (2003) também verificaram que a aplicação de uma lâmina equivalente a $75 \%$ da evapotranspiração medida em lisímetro de drenagem associada a uma dose de $0,675 \mathrm{~kg}$ de $\mathrm{K}_{2} \mathrm{O}$ por planta proporcionou maior produtividade comercial, sendo a mesma da ordem de 40.989,47 kg hä.- Suassuna et al. (2011) avaliaram o efeito da irrigação no rendimento e qualidade da produção do maracujazeiro amarelo e verificaram que o maior percentual de produção de frutos com massa média igual ou superior a $150 \mathrm{~g}$ (classe A) foi obtido com a lâmina de $120 \%$ da ET.

Figueiredo et al. (2003), trabalhando em solos de cerrado com maracujá-doce irrigado, verificaram que a irrigação deve ser realizada toda vez que a tensão de água no solo atingir valores próximos a $54 \mathrm{kPa}$ e que o volume de água necessário para a irrigação situam-se próximos a 52 e $87 \mathrm{~L}_{\text {planta }}{ }^{-1}$, no primeiro e segundo ano, respectivamente. Os resultados obtidos por Carvalho et al. (2010), na primeira safra do maracujá amarelo, indicam que a irrigação pode ser realizada quando a tensão da água no solo atingir $60 \mathrm{kPa}$.

Alencar (2000), trabalhando com lisímetros de drenagem e o método de Penmam-Montheith, estimou o coeficiente de cultura $(\mathrm{Kc})$ e a evapotranspiração (ETc) do maracujá-amarelo na região de Piracicaba/SP e verificou que a ETc atingiu o valor máximo $\left(4,68 \mathrm{~mm} \mathrm{dia}^{-1}\right)$ no período compreendido entre 182 e 196 dias após o transplantio e o Kc, no período entre 84 e 186 dias após o transplantio, aumentou de 0,51 a 1,10 , sendo o valor médio no período anterior de 0,41 . O maior consumo de água do maracujazeiro ocorreu no inicio da floração e frutificação. Silva e Klar (2002) avaliaram o consumo de água do maracujazeiro amarelo na região de Botucatu/SP no período de setembro/2000 a julho/2001, sendo a evapotranspiração máxima da cultura $(\mathrm{ETc})$ e de referência $\left(\mathrm{ET}_{\mathrm{o}}\right)$ medidas em lisimetros de lençol freático constante. Os autores verificaram que os valores de $\mathrm{Kc}$ variaram de 0,42 a 1,12, com valores máximos registrados nos períodos correspondentes aos estádios fenológicos de florescimento e formação de frutos, ou seja, 150 a 210 dias após os transplantio das mudas. Os maiores valores de Kc obtidos pelos autores para as duas regiões foram semelhantes e ocorreram nas mesmas fases 
fenológicas, entretanto, na região de Botucatu, o inicio do florescimento foi mais precoce devido, provavelmente, às diferentes condições de cultivo e época de transplantio, uma vez que em Botucatu foi realizado em setembro e em Piracicaba foi em maio.

De acordo com Carvalho et al. (2010), algumas regiões do sul de Minas Gerais têm apresentado, nos últimos anos, uma expansão da área plantada com maracujazeiro amarelo cuja produção, em sua maioria, é absorvida pelas indústrias de suco. Porém a produtividade alcançada ainda é pequena, o que se deve à falta de conhecimento e de adoção de tecnologias apropriadas à cultura na região.

Há um consenso de que o uso da irrigação pode prolongar o período de produção, promover acréscimo na produção e melhorar a qualidade dos frutos e, assim, é importante desenvolver pesquisa que possa definir o manejo de irrigação para orientar os produtores irrigantes. Com base no exposto, este trabalho teve por objetivo avaliar o efeito de diferentes níveis de tensões de água no solo na produção e qualidade dos frutos do maracujá-amarelo.

\section{MATERIAL E MÉTODOS}

O experimento foi conduzido de agosto de 2007 a fevereiro de 2008, na terceira safra de uma cultura de maracujá-amarelo (Passiflora edulis Sims f. flavicarpa Deg). O trabalho foi realizado na área experimental do Departamento de Engenharia da Universidade Federal de Lavras (UFLA), em Lavras, MG, localizada na região Sul do Estado de Minas Gerais, a $918 \mathrm{~m}$ de altitude, $21^{\circ} 14^{\prime} \mathrm{S}$ de latitude e $45^{\circ} 00^{\prime} \mathrm{W}$ de longitude, cujo solo é classificado como Latossolo Vermelho Distrófico Típico (EMBRAPA, 1999).

De acordo com a classificação de Köeppen, a região apresenta um clima Cwa, ou seja, clima temperado suave, chuvoso, com inverno seco, temperatura média do mês mais frio, inferior a 18 ${ }^{\circ} \mathrm{C}$ e superior a $3{ }^{\circ} \mathrm{C}$, o verão apresenta temperatura média do mês mais quente, superior a $22{ }^{\circ} \mathrm{C}$ (DANTAS et al., 2007).

O delineamento experimental utilizado foi o de blocos casualizados (DBC), com quatro tratamentos e quatro repetições. Os tratamentos consistiam de níveis de tensão da água no solo, correspondentes a $15 \mathrm{kPa}\left(\mathrm{L}_{1}\right), 30 \mathrm{kPa}\left(\mathrm{L}_{2}\right), 45 \mathrm{kPa}\left(\mathrm{L}_{3}\right)$ e $60 \mathrm{kPa}$ $\left(\mathrm{L}_{4}\right)$. O tratamento $15 \mathrm{kPa}$ (L1) foi considerado testemunha. Cada parcela foi constituída por duas plantas úteis, sem bordadura. Nas análises estatísticas, os níveis de tensão de água no solo foram analisados pela analise de variância.

A caracterização física e química do solo, na época de implantação, foi realizada no Departamento de Ciência do Solo da UFLA com amostras de solo retiradas nas camadas de 0,00$0,20 \mathrm{~m}$ e $0,20-0,40 \mathrm{~m}$. As equações 1 (camada de 0,00-0,20 m) e 2 (camada de 0,20-0,40 m) representam a curva de retenção de água no solo.

$$
\begin{aligned}
& \theta=0,235+\left(\frac{0,474-0,235}{\left[1+(\psi * 0,2749)^{2,072}\right]^{0,5067}}\right) \\
& \theta=0,263+\left(\frac{0,473-0,263}{\left[1+(\psi * 0,2468)^{2,1094}\right]^{0,5259}}\right)
\end{aligned}
$$

$\mathrm{Na}$ época do plantio (jan/2005), o preparo do solo consistiu de duas gradagens e incorporação de 1,55 $\mathrm{t} \mathrm{ha}^{-1}$ de calcário dolomítico para elevação da saturação por base a $80 \%$. As adubações de formação e produção foram realizadas para uma produtividade esperada superior a $35 \mathrm{t}^{\text {ha }}$ 1. Em setembro de 2007 foi realizada a análise de fertilidade do solo e, com base no resultado e recomendações da $5^{\text {a }}$ Aproximação (CFSEMG, 1999), foi aplicado $22,68 \mathrm{~kg}$ de calcário e, utilizando a Ureia como fonte de $\mathrm{N}$ e o Cloreto de Potássio como fonte de $\mathrm{K}_{2} \mathrm{O}$, foram aplicados, em 3 parcelamentos, $0,100 \mathrm{~kg} \mathrm{~N}$ planta $^{-1}$ e 0,090 $\mathrm{kg}$ de $\mathrm{K}_{2} \mathrm{O}$ planta $^{-1}$. Em Janeiro/2008, foi aplicado $0,030 \mathrm{~kg}_{\text {planta }}{ }^{-1} \mathrm{de}_{2} \mathrm{P}_{5}$, na forma de Superfosfato Simples.

$\mathrm{O}$ espaçamento adotado foi de $2,0 \mathrm{~m}$ entre plantas e 1,75 m entre linhas de plantas. As plantas foram conduzidas em espaldadeiras verticais, com um fio de arame liso, preso e esticado por mourões espaçados de quatro metros que estavam intercalados por dois bambus entre as plantas, distanciados $1,0 \mathrm{~m}$ entre si. As plantas foram conduzidas com dois ramos laterais, crescendo de forma controlada, de maneira que os ramos das 
duas plantas fossem conduzidos dentro do limite de tratamento estabelecido de $4 \mathrm{~m}$. Devido a um maior adensamento das plantas, foi necessária também a poda das gavinhas e dos ramos, mantendo-os a uma distância de $0,30 \mathrm{~m}$ do solo.

Foram realizadas, sempre que ocorriam sintomas, pulverizações com inseticidas e fungicidas para o controle de pragas e doenças. Realizaram-se também pulverizações com micronutrientes à medida que os sintomas de deficiências eram observados. O controle de ervas daninhas foi feito por meio de capina. Foi realizada a polinização artificial. O início da abertura de flores ocorreu em 27/09/07.

A colheita dos frutos começou em 11/12/2007, estendendo-se até fevereiro de 2008. A maioria dos frutos foi colhida ainda no estádio préclimatérico, caracterizado pela mudança na cor verde para amarela, além dos frutos que caíam esporadicamente.

Utilizou-se do sistema de irrigação por gotejamento. Em cada tratamento havia uma linha de irrigação com quatro gotejadores autocompensantes por planta, com vazão de $2,3 \mathrm{~L}$ $\mathrm{h}^{-1}$, distanciados $0,40 \mathrm{~m}$ entre si, possibilitando a aplicação das quantidades de água por planta em função do tratamento de irrigação pré-estabelecido. O momento de irrigação foi definido pelo potencial mátrico da água no solo, medido em tensiômetros instalados a $0,15 \mathrm{~m}$ da planta e a $0,20 \mathrm{~m}$ de profundidade. Irrigava-se toda vez que o potencial mátrico medido a $0,20 \mathrm{~m}$ de profundidade atingia o valor próximo a $15 \mathrm{kPa}, 30 \mathrm{kPa}, 45 \mathrm{kPa}$ e $60 \mathrm{kPa}$ de cada tratamento. Para isso, foi instalada uma bateria de quatro tensiômetros de punção para as tensões de $15 \mathrm{kPa}$ a $60 \mathrm{kPa}$, sendo um tensiômetro para cada repetição do tratamento, totalizando 16 tensiômetros. As leituras nos tensiômetros foram realizadas diariamente entre 7 e 9 horas, utilizando leitor digital de punção.

Para o cálculo do volume de irrigação, necessário a cada tratamento, utilizou-se o percentual de uma área molhada de $50 \%$ da projeção da copa para o calculo do volume total forte. A quantidade de água aplicada na cultura do maracujazeiro foi determinada pela Equação 3. A profundidade efetiva do sistema radicular, considerada nestes experimentos, foi de $0,30 \mathrm{~m}$.

$$
V=\left(\theta_{c c}-\theta\right)(A Z 0,5)
$$

em que,

$\mathrm{V}$ - volume $\left(\mathrm{m}^{3}\right) ; \theta_{\mathrm{cc}}$ - umidade na capacidade de campo $\left(\mathrm{m}^{3} \mathrm{~m}^{-3}\right)$;

$\theta$ - umidade atual a base de volume $\left(\mathrm{m}^{3} \mathrm{~m}^{-3}\right)$;

A - área total $\left(\mathrm{m}^{2}\right)$;

$\mathrm{Z}$ - profundidade efetiva do sistema radicular (m).

O tempo de irrigação, em minutos, foi calculado utilizando-se a Equação 4:

$\mathrm{T}=\left(\frac{\mathrm{V}}{\mathrm{q}}\right)$

em que,

T - tempo de irrigação (min);

$\mathrm{V}$ - volume $\left(\mathrm{m}^{3}\right)$;

q - vazão dos gotejadores por planta $\left(\mathrm{m}^{3} \mathrm{~h}^{-1}\right)$.

Os frutos colhidos foram pesados em balança de precisão e medidos o comprimento e diâmetro de frutos com paquímetro digital. Após efetuada cada colheita, os frutos foram classificados e a produtividade dividida em frutos comerciais e nãocomerciais. Foram considerados frutos de valor comercial aqueles com peso acima de $45 \mathrm{~g}$ e com boa aparência, sem deformações, enquanto que frutos danificados ou estragados foram considerados aqueles com sintomas de ataque de pragas ou doenças e com peso de fruto inferior a $45 \mathrm{~g}$.

A classificação dos frutos foi feita por peso de acordo com a classificação adotada pelo mercado atacadista da CEAGESP, apresentada em Meletti \& Maia (1999), em 5 tipos: Extra AAA (>173 g), Extra AA (144 - 173 g), Extra A (108-144 g), Extra $(86-108 \mathrm{~g})$ e Especial $(45-86 \mathrm{~g})$.

As análises estatísticas foram realizadas utilizando o programa SISVAR, versão 4.3 (FERREIRA, 2011).

\section{RESULTADOS E DISCUSSÃO}

No Quadro 1 estão relacionados os dados de precipitação e das lâminas de irrigação aplicadas 
durante o período de condução do experimento, compreendido entre agosto de 2007 a fevereiro de 2008. Neste período, a lâmina total aplicada (precipitação + irrigação) variou de $1.530,59$ a 1.066,78 mm. De acordo com Lima et al. (1999), o maracujá se adapta melhor em regiões em que a precipitação média esteja entre 800 e $1.700 \mathrm{~mm}$ e seja bem distribuída ao longo do ano. Considerando somente a precipitação como fonte de fornecimento de água à cultura, a lâmina aplicada estaria próximo ao limite inferior ao requerido e também com uma distribuição temporal que não possibilitaria um desenvolvimento adequado, o que poderia comprometer a produção. Souza et al. (2005) verificaram que os maiores rendimentos de frutos comerciais do maracujazeiro amarelo, irrigados por gotejamento, foram obtidos com a aplicação de lâminas variando entre $1.528,2$ e $2.117,28$ L planta $^{-1}$ ano $^{-1}$.

Durante o período experimental, foram realizadas $24,12,5$ e 3 irrigações nos tratamento L1, L2, L3 e L4, respectivamente. Pode-se verificar que a lâmina total aplicada no tratamento irrigado, quando a tensão de água no solo atingia $60 \mathrm{kPa}$, foi equivalente a $23,6 \%$ do volume aplicado no tratamento de $15 \mathrm{kPa}$.

No Quadro 2 apresentm-sea os dados da análise de variância do peso comercial (PC), peso não comercial $(\mathrm{PCN})$, comprimento e diâmetro dos frutos colhidos. Verifica-se que os tratamentos de lâmina adotados não influenciaram significativamente nenhuma das características

Quadro 1. Valores de lâminas de água mensais e totais provenientes de precipitação pluviométrica (P) e aplicada pela irrigação (L) nos diferentes tratamentos

\begin{tabular}{lccccc}
\hline \multirow{2}{*}{ Meses } & $\mathrm{P}$ & \multicolumn{4}{c}{ Lâmina $\left(\mathrm{mm} \mathrm{planta}^{-1}\right)$} \\
& $\mathrm{mm}$ & $\mathrm{L}_{1}(15 \mathrm{kPa})$ & $\mathrm{L}_{2}(30 \mathrm{kPa})$ & $\mathrm{L}_{3}(45 \mathrm{kPa})$ & $\mathrm{L}_{4}(60 \mathrm{kPa})$ \\
\hline Ago & 0 & 133,14 & 122,39 & 91,15 & 95,51 \\
Set & 0 & 143,56 & 157,09 & 91,15 & 48,17 \\
Out & 130,1 & 154,63 & 124,64 & 0,00 & 0,00 \\
Nov & 110,4 & 72,09 & 0,00 & 0,00 & 0,00 \\
Dez & 176,6 & 71,06 & 41,03 & 0,00 & 0,00 \\
Jan & 263,0 & 32,21 & 41,5 & 0,00 & 0,00 \\
Fev & 243,0 & 0 & 0,00 & 0,00 & 0,00 \\
\hline Total & 923,1 & 607,49 & 486,65 & 226,77 & 143,68 \\
\hline P + L & - & 1530,59 & 1409,75 & 1149,87 & 1066,78 \\
\hline
\end{tabular}

Quadro 2. Analise de variância de peso comercial (PC) e peso não comercial (PNC) em kg e comprimento $(\mathrm{mm})$ e diâmetro $(\mathrm{mm})$ dos frutos de frutos de maracujá

\begin{tabular}{lccccc}
\hline FC & G & & \multicolumn{3}{c}{ QM } \\
& & PC & PNC & Comprimento & Diâmetro \\
Bloco & 3 & $0,00033998^{\mathrm{NS}}$ & $0,00264307^{\mathrm{NS}}$ & $18,70769^{\mathrm{NS}}$ & $7,99289^{\mathrm{NS}}$ \\
Lâmina & 3 & $0,00008156^{\mathrm{NS}}$ & $0,00011297^{\mathrm{NS}}$ & $7,10706^{\mathrm{NS}}$ & $4,32310^{\mathrm{NS}}$ \\
Resíduo & 7 & 0,00018182 & 0,00098382 & 21,86119 & 5,94706 \\
CV (\%) & & 7,26 & 22,05 & 5,25 & 3,32 \\
Média & & 0,184 & 0,140 & 88,42 & 73,21 \\
\hline
\end{tabular}

NS não significativo 
avaliadas, provavelmente devido à contribuição da precipitação. Silva et al. (2004), trabalhando com maracujá doce, verificaram que a irrigação não influenciou significativamente a massa dos frutos, o comprimento e o diâmetro e que a falta de efeito da irrigação, provavelmente, seja devido a alta precipitação ocorrida durante o período de condução do experimento. A massa, comprimento e diâmetro médios dos frutos obtidos pelos autores foram de 198,63 g, 10,71 cm e 7,15 cm, respectivamente, valores superiores aos obtidos neste trabalho. Os dados dos parâmetros físicos do fruto (peso, comprimento e diâmetro) do maracujazeiro colhidos entre dezembro de 2005 e março de 2006, na mesma área experimental, não foram influenciados pelos tratamentos de irrigação (KOETZ et al., 2010).

Os valores de peso verificados neste trabalho foram superiores àqueles obtidos por Souza et al. (2003), que também não observaram diferença significativa em função das lâminas aplicadas. Entretanto, Carvalho et al. (2000), obtiveram frutos com peso médio entre $0,147 \mathrm{~kg}$ e $0,161 \mathrm{~kg}$, que foram significativamente influenciados pelas lâminas de irrigação aplicadas. Suassuna et al. (2011), verificaram que as plantas irrigadas com lâmina equivalentes a $140 \%$ de ETo apresentaram redução de $22,83 \%$ na massa média dos frutos quando comparado com tratamento irrigado com $120 \%$ de ETo, indicando que o excesso de água prejudicou o ganho de massa dos frutos de maracujá.

O comprimento e diâmetro dos frutos do maracujazeiro são importantes indicadores para sua seleção no mercado de frutas frescas, uma vez que os frutos maiores são mais valorizados. Segundo Negreiros et al. (2007), os frutos com maior diâmetro equatorial possibilita obtenção de maracujás mais pesados e com maior rendimento de polpa, uma vez que o diâmetro tem maior efeito direto sobre o peso da polpa e rendimento.

Conforme Akamine e Girolami (1959), citados por Souza (2000), as dimensões dos frutos do maracujazeiro amarelo variam de 60 a $120 \mathrm{~mm}$ de comprimento e de 40 a 70 mm de diâmetro. Assim, os valores médios para comprimento e diâmetro de frutos registrados neste trabalho estão dentro das faixas consideradas ideais para a cultura e foram superiores aos valores obtidos por Carvalho et al. (2000), que foram da ordem de 73,7 mm e 69,5 mm para comprimento e diâmetro, respectivamente.

A análise de variância referente à classificação dos frutos esta relacionada no Quadro 3. Observase que os tratamentos adotados não influenciaram significativamente na classificação dos frutos.

Os frutos da classe Extra AAA foram os que mais contribuíram para a produtividade comercial representando, em média, 58,3\%, seguido pelas classes Extra AA, Extra A, Extra e Especial, com 18,2, 15,4, 5,2 e 2,9\%, respectivamente, conforme pode ser verificado na Figura 1. A classificação dos frutos é importante uma vez que padroniza os frutos em função do tamanho, peso e coloração, possibilitando obter melhores preços na comercialização, além de ser mais atrativo aos consumidores. De acordo com Cavichioli et al. (2008), os consumidores preferem frutos com massa superior a 170 gramas e, como pode

Quadro 3. Analise de variância em função das classes de classificação de frutos de maracujá. UFLA, Lavras/MG, 2008

\begin{tabular}{lcccccc}
\hline \multirow{2}{*}{ FV } & G & \multicolumn{5}{c}{ QM } \\
\cline { 3 - 7 } & & Extra AAA & Extra AA & Extra A & Extra & Especial \\
\hline Bloco & 3 & $0,19182^{\mathrm{NS}}$ & $1,09909^{\mathrm{NS}}$ & $1,09106^{\mathrm{NS}}$ & $0,26390^{\mathrm{NS}}$ & $0,21989^{\mathrm{NS}}$ \\
Lâmina & 3 & $0,30616^{\mathrm{NS}}$ & $0,57059^{\mathrm{NS}}$ & $0,14631^{\mathrm{NS}}$ & $0,50045^{\mathrm{NS}}$ & $0,42907^{\mathrm{NS}}$ \\
Resíduo & 7 & 0,31872 & 0,44840 & 0,71705 & 0,67474 & 0,27347 \\
\hline CV (\%) & 10,48 & 21,90 & 30,31 & 46,34 & 45,94 \\
Média & 101 & 32 & 27 & 9 & 5 \\
\hline
\end{tabular}

${ }^{\mathrm{NS}}$ não significativo 
ser observado na Figura 1, esta características prevaleceu em todos os tratamentos de irrigação adotados neste trabalho. Nos trabalhos realizados por Meletti e Maia (1999) e por Koetz (2006) foi observado que os frutos de maracujá tipo Extra AAA foram os que mais contribuíram para o total da produtividade comercial, representando $31,82 \%$ e $55,11 \%$ da produtividade média, respectivamente.

O maior percentual de frutos na classe Extra AAA observados neste trabalho se deve, provavelmente, à época em que foi realizado o experimento. Uma vez que o maracujazeiro é uma cultura típica de clima tropical, as condições prevalecentes na região favoreceram a produção de frutos maiores.

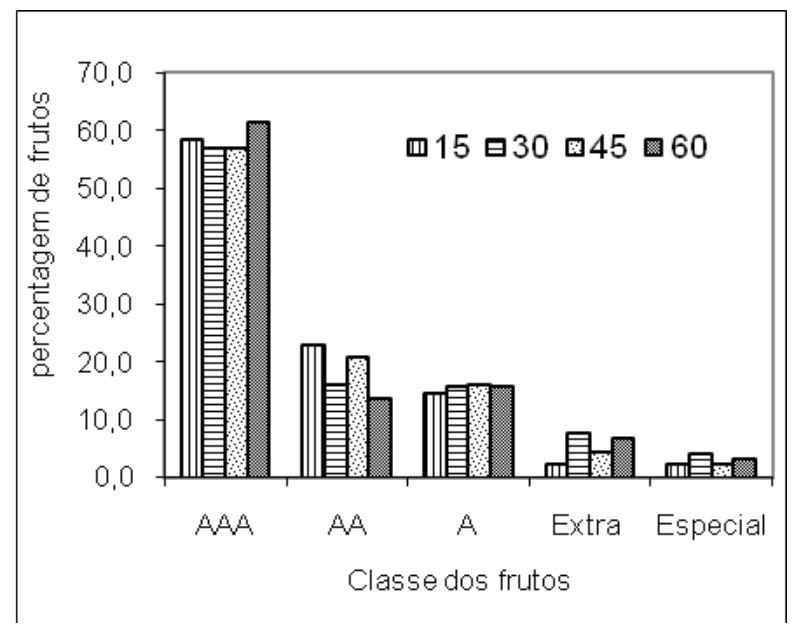

Figura 1. Percentagem de frutos distribuídos entre as classes em função tensões de água no solo, adotadas em cada tratamento. UFLA, Lavras/MG, 2008.

\section{CONCLUSÃO}

- A irrigação no maracujazeiro pode ser realizada sob a tensão de água no solo a $60 \mathrm{kPa}$ sem prejuízos na produção e na qualidade dos frutos.

\section{REFERÊNCIAS BIBLIOGRÁFICAS}

ALENCAR, C.M. Consumo de água do maracujazeiro-amarelo (Passiflora edulis Sims. F. flavicarpa Deg.). 2000. 49f. Dissertação (Mestrado em Agronimis) - Escola Superior de Agricultura "Luiz de Queiroz", Universidade de São Paulo, Piracicaba, 2000.
CARVALHO, J.A.; KOETZ, M.; SOUSA, A.M.; SOUZA, K.J. de. Desenvolvimento e produtividade do maracujazeiro-amarelo irrigado sob diferentes lâminas de irrigação em ambiente protegido e natural. Engenharia Agrícola, Jaboticabal, v.30, n.5, p.862-874, 2010.

CARVALHO, A.J.C. de; MARTINS, D.P.; MONNERAT, P.H.; BERNARDO, S. Adubação nitrogenada e irrigação no maracujazeiro-amarelo. I. Produtividade e qualidade dos frutos. Pesquisa Agropecuária Brasileira, Brasília, v.35, n.6, p.1101-1108, 2000.

CAVICHIOLI, J.C.; RUGGIERO, C.; VOLPE, C.A. Caracterização físico-química de frutos de maracujazeiro-amarelo submetidos à iluminação artificial,irrigação e sombreamento. Revista Brasileira de Fruticultura, Jaboticabal, v.30, n.3, p.649-656, 2008.

CFSEMG - COMISSÃO DE FERTILIDADE DO SOLO DO ESTADO DE MINAS GERAIS. Maracujá: Recomendações para o uso de corretivos e fertilizantes em Minas Gerais. $5^{\text {a }}$ aproximação. Viçosa, 1999. p.289-302.

DANTAS,A.A.A.,CARVALHO,L.G.;FERREIRA, E. Classificação e tendências climáticas em Lavras, MG. Ciência e Agrotecnologia, Lavras, v.31, n.6, p.1862-1866, 2007.

EMPRESA BRASILEIRA DE PESQUISA AGROPECUÁRIA. Sistema Brasileiro de classificação de solos. Brasília, 1999, 412p.

FERREIRA, D.F. SISVAR: a computer statistical analysis system. Ciência e Agrotecnologia, Lavras, v.35, n.6, p.1039-1042, 2011.

FIGUEIREDO, S.F.; AZEVEDO, J.A.; ANDRADE, L.M.; JUNQUEIRA, N.T.V.; ANDRADE, L.R.M.; GOMES, A.C. Produtividade do maracujá-doce em resposta à níveis de tensão de água e fertirrigação nitrogenada, em solo de cerrado. Disponível em: < http://bbeletronica.cpac. embrapa.br/2003/posteres2003/p2003_19pdf $>$. Acesso em: 13/03/2013. 
IBGE, Instituto Brasileiro de Geografia e Estatística. disponível em: <www.sidra.ibge.gov. br/>Acesso em: 11/03/2013.

KOETZ, M. Maracujazeiro-amarelo: cultivo protegido e natural, irrigação e adubação potássica. 2006. 119f. Tese (Doutorado em Engenharia Agrícola) - Universidade Federal de Lavras, 2006

KOETZ, M.; CARVALHO, J.A.; SOUZA, A.M.G. de; SOUZA, K.J. de. Qualidade dos frutos do maracujazeiro-amarelo em ambiente protegido e natural produzidos sob diferentes regimes de irrigação. Revista Brasileira de Agricultura Irrigada, Fortaleza, v.4, n.2, p.115-126, 2010.

LIMA, A.A.; BORGES, A.L.;CARDOSO, C.E.L.; BARBOSA, C.J.; COSTA, D.C.; SANTOS FILHO, H.P.; FANCELLI, M.; SANCHES, N.F. A cultura do maracujá, 2 ed. rev. aum. Embrapa Mandioca e Fruticultura. Brasília: Embrapa Comunicação para transferência de Tecnologia, 1999, 107p; 16 cm. Coleção Plantar, 41.

MELETTI, L.M.M.; MAIA, M.L. Maracujá: produção e comercialização. Boletim Técnico do Instituto Agronômico de Campinas, Campinas, n.181, p.2-26, 1999.

NEGREIROS. J.R.L.S.; ALVARES, V.S.; BRUCKNER, C.H.; MORGADO, M.A.D.; CRUZ, C.D. Relação entre as características físicas e rendimento de polpa de maracujá amarelo. Revista Brasileira de Fruticultura, Jaboticabal/SP, v.29, n.3, p.546-549, 2007.

SILVA, H.D.; CORRÊA, L.S.; BOLIANI. A.C. Efeitos do sistema de condução, poda e irrigação na produção do maracujazeiro doce. Revista Brasileira de Fruticultura, Jaboticabal, v.26, n.3, p.450-453, 2004.

SILVA, A.A.G.; KLAR, A.E. Demanda hídrica do maracujazeiro amarelo (Passiflora edulis Sims. F. flavicarpa Deg.). Irriga, Botucatu, v.7, n.3, p.185190, 2002.

SOUZA, V.F.; FRIZZONE, J. A.; FOLEGATTI, M.V.; VIANA, T.V. de A. Eficiência do uso de água pelo maracujazeiro amarelo sob diferentes níveis de irrigação e doses de potássio. Revista Brasileira de Engenharia Agrícola e Ambiental, Campina Grande, v.9, n.3, p.302-306, 2005.

SOUZA, V.F.; FOLEGATTI, M.V.; FRIZZONE, J. A.; CORRÊA, R.A.L.; ELOI, W.M. Produtividade do maracujazeiro amarelo sob diferentes níveis de irrigação e doses de potássio via fertirrigação. Pesquisa Agropecuária Brasileira, Brasília, v.38, n.4, p.497-504, 2003.

SOUZA, V.F.; FOLEGATTI, M.V.; COELHO FILHO, M.A.; FRIZZONE, J.A. Distribuição radicular do maracujazeiro sob diferentes doses de potássio aplicadas por fertirrigação. Revista Brasileira de Engenharia Agrícola e Ambiental, Campina Grande, v.6, n.1, p.51-56, 2002.

SOUZA, V.F. Níveis de irrigação e doses de potássio aplicados via fertirrigação por gotjamento no maracujazeiro-amarelo (Passiflora edulis Sims. F. flavicarpa Deg.). 2000. 178f. Tese (Doutorado em Irrigação e Drenagem) Escola Superior de Agricultura "Luiz de Queiroz", Universidade de São Paulo, Piracicaba, 2000.

SUASSUNA, J.F.; MELO, A.S.; FERRAZ, R.L.S.; PEREIRA, V.M.; SOUSA, M.S.S. Rendimento e qualidade da produção de híbrido de maracujazeiroamarelo "IAC 273/277" sob diferentes níveis de irrigação. Revista Caatinga, Mossoró, v.24, n.4, p.115-122, 2011.

ZERAIK, M.L.; PEREIRA, C.A.M.; ZUIN, V.G.; YARIWAKE, J.H. Maracujá: um alimento funcional? Revista Brasileira de Farmacognosia, São Carlos, v.20, n.3, p.459-471, 2010. 